\title{
SUPUESTOS EPISTEMOLÓGICOS QUE SUBYACEN A LA INNOVACIÓN EDUCATIVA
}

\section{Licda. Jacqueline García Fallas}

\section{Resumen}

En este artículo se propone un análisis del tema de la innovación educativa desde una perspectiva epistemológica, según la cual se considera los supuestos institucionales y filosóficos que subyacen en el ámbito de ese tema.

Se propone un acercamiento crítico a ese ámbito como parte de la práctica docente, pero cuyas implicaciones epistemológicas lo trascienden al legitimar ciertas pautas institucionales que cambian la visión de lo que se entiende por innovar en el campo educativo.

La experiencia de innovar es un ámbito necesario en cualquier área de trabajo, sea administrativa o docente, en los niveles educativos, o en cualquier modalidad. Es relevante destacar que esta experiencia forma parte del quehacer cotidiano en cada centro educativo, se expresa como estrategias pedagógicas, propuestas curriculares o proyectos pedagógicos, pero no siempre la innovación surge de la experiencia y de la reflexión sobre lo que las docentes y los docentes consideran como transformación del espacio pedagógico en procura de aulas creativas. La razón de esta situación es la percepción de una innovación educativa ajena a la práctica pedagógica de cada profesional y muchas veces transferida de otros espacios pedagógicos y contextos socio-culturales.

\section{Planteamiento del tema y justificación.}

La formación profesional de una persona que se desempeña en el campo educativo demuestra la confluencia de una serie de teorías, de visiones, de creencias sobre cómo enseñar, cómo se aprende, cuáles son las estrategias más importantes que se pueden poner en práctica y de qué manera, para lograr un mejor aprovechamiento del espacio pedagógico y de los procesos de aprendizaje (Charlier, B. 1998). Esa confluencia se expresa en la forma en que cada docente se define a sí mismo como persona y como profesional, pero también en lo que enseña y en cómo lo enseña. Esa síntesis que identifica el trabajo de cada docente no siempre es percibida de forma clara y consciente, la mayoría de las ocasiones es un saber hacer construido a partir de las distintas experiencias y sin poder identificar qué aspectos forman parte de bagaje de conocimientos y de creencias, los cuales se han constituido en los principios por los que cobra sentido la práctica profesional (Barth, B.M. 1993).

No obstante es común que las docentes y los docentes busquen cómo mejorar su práctica pedagógica, por ejemplo, con nuevas formas de enseñar, con el diseño de materiales didácticos, con la incorporación de medios audio-visuales y tecnológicos (Charlier, 
B. 1998). Este interés por renovar sus experiencias en el aula es promovido también por otros actores educativos: los padres de familia, los estudiantes, el o la directora, el asesor, el Ministerio de Educación Pública o una instancia similar, por ejemplo, los centros de formación docente.

A manera de síntesis en el campo educativo la expectativa por el cambio se encuentra en la administración educativa y en la gestión pedagógica. Sin embargo esa expectativa no siempre es atendida desde los intereses de los actores educativos, sino que en la mayoría de los casos se transforma en propuestas de innovación educativa provenientes de cómo otros conciben mejorar la práctica pedagógica. Se incluyen antecedentes y éxitos ocurridos en sectores socioculturales muy diversos entre sí, como los indicadores de la potencialidad de tales propuestas en los escenarios pedagógicos, sin considerar las visiones, las concepciones y las creencias de los que han obtenido éxito con algunas propuestas y su relación con las visiones, las concepciones y las creencias de quienes recibirán esas propuestas.

Desde esta perspectiva cobra sentido un análisis de los supuestos epistemológicos que subyacen a la innovación educativa.

\section{Desarrollo del trabajo}

\subsection{Un acercamiento a la noción de innovar}

Con frecuencia la palabra innovar hace referencia a las nociones de cambio, de hacer algo nuevo, de mejorar. A partir de esas tres acepciones es evidente que esa palabra está asociada con alguien que se da cuenta de la realización de algo distinto, quizás diferente a lo que siempre ha hecho. Esa reflexión crítica supone la incorporación paulatina de una serie de experiencias sobre lo que se hace para replantear y proponer otras formas de hacer. La noción de cambio conlleva la idea de un proceso, el cual es resultado de una apropiación constante de la propia práctica. Así lo nuevo no es lo espontáneo, sino la consecuencia de un "empoderamiento" de la práctica pedagógica. También se sugiere que la innovación responde a un desarrollo individual más que general de esa práctica (Charlier, B. 1998).

\subsection{Supuestos institucionales de la experiencia de innovar en el campo educativo}

A partir de ese acercamiento de la noción de innovar se puede afirmar que la innovación educativa es propuesta como una exigencia generalizable a otros contextos y a otras experiencias pedagógicas. Esa innovación responde a lo que otros creen que se debería hacer en el campo educativo (Gregoire, J.. 1996).

Es importante poder distinguir por qué las planificaciones sobre innovación educativa responden a una forma de concebir el campo educativo. Esa forma se encuentra en la clásica teoría de sistemas. Aquella se expresa en términos de un "in put " y de un "out put". Con una visión de proceso estructurada a partir de lo que se tiene, lo que se pretende como experiencia innovadora se introduce como un elemento ajeno dentro de un sistema ya constituido, es decir en una forma de concebir cómo se enseña, cómo se aprende y de qué manera. Ese elemento tendrá que encontrar alguna afinidad en lo que ya se hace y una paulatina identificación con lo que se podría hacer. Sin embargo, no siempre es posible que 
ese elemento propicie un cambio importante en lo que se hace, especialmente por tratarse de un elemento que se adhiere a una práctica pedagógica ya constituida y a lo mejor no requiere de ese elemento para propiciar una transformación en su práctica pedagógica porque éste no concuerda con su visión, su concepción y sus creencias sobre lo que es y debería ser un espacio pedagógico.

Así ese panorama genera un sentimiento de extrañamiento por el que las docentes y los docentes no se apropian de lo que se ha propuesto como una innovación educativa. Por ejemplo las decisiones de los centros de formación docente y de las autoridades educativas ministeriales marcan el desarrollo de ciertas tendencias y acciones educativas, las cuales no siempre responden a los intereses, las visiones, las concepciones y las creencias de quienes llevan a cabo una práctica pedagógica.

Esta situación responde a una consecuencia lógica de la teoría de sistemas que se ha descrito, ese elemento se percibe como algo no propio, ni necesario para ser incorporado en una práctica pedagógica que siempre se ha realizado y a lo mejor se han obtenido los resultados que se esperaba, entonces para qué cambiar esa práctica.

La teoría de sistemas funciona como un recurso ideológico que prescribe un camino para obtener un resultado. En el campo educativo el conocimiento de esta teoría permite planificar y ejecutar procesos bajo una óptica definida por el sistema. Esta situación trae como consecuencia un tener que apegarse a lo dispuesto en el sistema, cuando en la práctica la situación educativa puede ser muy diferente. Además, esta teoría reafirma la visión del personal docente que ejecuta las directrices del sistema, pero no lo crea; por tal razón esas directrices se convierten en elementos que se agregan al sistema sin que hayan sido avaladas y reconocidas por el equipo de profesionales.

A la par de esta consecuencia también se presenta otra. Las propuestas de innovación educativa no responden a los intereses y a las necesidades que tienen las docentes y los docentes, por lo que se asumen con apatía y sin confianza en lo que se producirá en sus espacios pedagógicos. En estos casos es posible aplicar el viejo refrán "más vale diablo conocido que por conocer".

\subsection{Supuestos epistemológicos de la innovación educativa}

El extrañamiento que provoca la asimilación de una propuesta de innovación educativa, así como la apatía, se fundamentan en la frase siguiente: "el medio es el mensaje", es decir si se introduce un elemento ajeno al sistema se genera una resistencia en el sistema no sólo institucional sino también en el de las visiones, las concepciones y las creencias de las docentes y los docentes.

Esta situación responde a una relación de poder que se transfiere de una estructura jerárquica institucional a una estructura personal constituida en práctica pedagógica. La principal dificultad es la existencia de un saber institucional verdadero frente a las experiencias que realizan las personas como prácticas pedagógicas (Berstein, B. 1996).

La falta de escucha en esa relación de poder dificulta el intercambio entre lo que se sabe, lo se podría hacer y lo que se podría cambiar para propiciar una apropiación crítica en la práctica pedagógica. Este aspecto es fundamental si se retoma la innovación como un 
proceso de cambio individual, en el que cada persona replantea su propia práctica pedagógica y la ajusta a sus necesidades e intereses.

Además la innovación educativa se transfiere sin la consideración del sistema de creencias, concepciones y visiones que cada docente ha constituido como su andamiaje para el desempeño en un aula, o en otro espacio, por ejemplo la dirección de un centro educativo.

La tensión provocada con frecuencia en las incoherencias entre la propuesta de una innovación educativa y la apropiación que cada docente hará de ésta, no siempre se analiza desde cómo este docente concibe su propia práctica pedagógica, sino que es impuesta como un recargo, una actividad insignificante o un exceso de trabajo (Sarason, S. 1983).

Así, la innovación educativa responde a supuestos epistemológicos que se caracterizan por perpetuar una relación de poder sin garantizar un intercambio entre distintas experiencias sobre prácticas pedagógicas, lo que se sabe y lo que se cree como mejor en cada práctica pedagógica, así como la distinción entre lo que se hace y por qué se hace. Es evidente que esta relación de poder no permite una apropiación de la práctica pedagógica y un discernimiento de cómo cambiar su propia práctica pedagógica como parte de un proceso de reflexión crítica sobre ésta, ya que no se valora lo que otros saben a cerca de su propia práctica pedagógica y el cambio está en manos de los que sí saben como debería ser esa práctica (Lafortune, L. \& Saint Pierre, L. 1998).

\section{Conclusión}

En síntesis, los supuestos epistemológicos acerca de la innovación educativa evidencian un funcionamiento desde la teoría de sistemas como parte de un elemento que se introduce en un sistema ya preestablecido, no sólo en la cultura escolar sino también en el sistema de creencias, visiones, concepciones que constituyen la forma en que cada docente realiza su práctica pedagógica. A partir de esa relación es comprensible el extrañamiento, la apatía y la imposición que sienten las docentes y los docentes con respecto a las propuestas de innovación educativa en su práctica pedagógica. Así mismo se impide una apropiación y "empoderamiento" de la propia práctica pedagógica, mediante una reflexión crítica sobre ésta.

\section{Referencias}

Barth, B.M. 1993. LE SAVOIR EN CONSTRUCTION. FORMER A UNE PEDAGOGIE DE LA COMPREHENSION. Paris: RETZ.

Berstein, B. 1996. PEDAGOGÍA, CONTROL SIMBÓLICO E IDENTIDAD. Madrid: Ediciones Morata.

\section{Charlier, B. 1998. APPRENDRE ET CHHANGER SA PRATIQUE D'} ENSEIGNEMENT. Bruxelles: De Boeck Université. 
Garton, A. 1994. INTERACCIÓN SOCIAL Y DESARROLLO DEL LENGUAJE Y LA COGNICIÓN. Madrid: Ediciones Paidós.

Gregoire, J.. 1996. EVALUATION DES APPRENTISSAGES. Bruxelles: De Boeck Université.

Lafortune, L. \& Saint Pierre, L. 1998. AFFECTIVITÉ ET METACOGNITION DANS LA CLASSE. Bruxelles: De Boeck Université.

Sarason, S. 1983. THE CULTURE OF THE SCHOOL AND A THE PROBLEM OF CHANGE. New York: Allyn and Bacon Inc. 